\title{
Correlation between levels of physical activity and anxiety and in patients with binge-eating disorder
}

\section{Correlación entre los niveles de actividad física y ansiedad en pacientes con trastorno de compulsión alimentar periódica}

\section{Correlação entre níveis de atividade física e ansiedade e em pacientes com transtorno da compulsão alimentar periódica}

\author{
da Silva Freire, A.A.1,4; dos Santos, D.1,4; Vaz, A.R.1; Lima, J.L.2; Axt, G.2; Murillo-Rodriguez, \\ E.3,4; Monteiro, D.s,7; Cid, L.6,7; Machado, S.2,4; Telles-Correia, D.
}

1University of Lisbon, Faculty of Medicine, Lisbon, Portugal.

2Laboratory of Physical Activity Neuroscience, Physical Activity Sciences Postgraduate Program, Salgado de Oliveira University (UNIVERSO), Niterói, Brazil.

3Laboratorio de Neurociencias Moleculares e Integrativas, Escuela de Medicina División Ciencias de la Salud, Universidad Anáhuac Mayab, Mérida, Mexico

4Intercontinental Neuroscience Research Group, Universidad Anáhuac Mayab, Mérida, Mexico.

sDepartment of Human Kinetics - ESECS - Polytechnic of Leiria; Research Center in Sport, Health and

Human Development (CIDESD).

6Sport Science School of Rio Maior, Polytechnique Institute of Santarém, Rio Maior, Portugal.

7Research Centre in Sports, Health and Human Development, CIDESD, Portugal.

\begin{abstract}
Binge-eating disorder (BED) is linked to several psychiatric disorders, such as anxiety disorders. Approximately 50$60 \%$ of BED patients are resistant to the traditional treatments available, and thus, strategies supporting the treatment of BED are needed, such as physical activity (PA). It seems to be an interesting strategy to reduce BED and anxiety symptoms. Thus, since PA has a role in reducing BED episodes and improving anxiety symptoms, then more research is needed to clarify the role of PA on BED, as correlations between anxiety-BED and anxiety-PA are established. Therefore, our aim is to examine the relationship between PA and anxiety in patients with BED. Thirty two patients we submitted to psychological and PA questionnaires. A Pearson's correlation coefficient and a multiple linear regression analysis were performed to relate eating disorder behaviour, anxiety and PA. The correlation coefficients between the dimensions of BED and anxiety were almost all significant (except restriction), positive and moderate $(\mathrm{p}<0.001)$. Thus, the higher the eating disorder values, the higher the anxiety levels $(\mathrm{p}<0.01)$. In conclusion, our findings support that PA correlates with anxiety in patients with BED, suggesting that PA may decrease symptoms, such as the appetite, weight and body shape concerns.
\end{abstract}

Keywords: anxiety, binge eating, exercise, physical activity.

RESUMEN 


\section{da Silva Freire, dos Santos, Vaz, Lima, Axt, Murillo-Rodriguez, Monteiro, Cid, Machado \& Telles- Correia}

El trastorno de compulsión alimentar periódico (TCAP) está vinculado a varios trastornos psiquiátricos, como los de ansiedad. Aproximadamente el 50-60\% de los pacientes con TCAP son resistentes a los tratamientos tradicionales disponibles y, por lo tanto, se necesitan estrategias que apoyen el tratamiento de TCAP, como la actividad física (AF). La práctica de AF parece ser una estrategia interesante para reducir TCAP y síntomas de ansiedad. Por lo tanto, dado que la AF tiene un papel en la reducción de los episodios de TCAP y en la mejora de los síntomas de ansiedad, entonces se necesita más investigación para aclarar el rol moderador de la AF en la TCAP, ya que se establecen correlaciones entre ansiedad-TCAP y ansiedad-AF. Por lo tanto, el objetivo de este estudio fue examinar la asociación entre AF y ansiedad en pacientes con TCAP. Treinta y dos pacientes fueron sometidos a cuestionarios psicológicos y de AF. Se realizaron un coeficiente de correlación de Pearson y un análisis de regresión lineal múltiple para relacionar el comportamiento del TCAP, la ansiedad y la AF. Los coeficientes de correlación entre las dimensiones del TCAP y ansiedad fueron casi todos significativos (excepto restricción), positivos y moderados ( $\mathrm{p}<0.001$ ). Por lo tanto, cuanto más altos sean los valores del TCAP, mayores serán los niveles de ansiedad ( $\mathrm{p}<0.01)$. En conclusión, nuestros hallazgos respaldan que la PA se correlaciona con la ansiedad en pacientes con BED, lo que sugiere que la PA puede disminuir los síntomas, como las preocupaciones sobre el apetito, el peso y la forma del cuerpo.

Palabras clave: ansiedad, compulsión alimenta, ejercício, actividad física.

\section{RESUMO}

O transtorno da compulsão alimentar periódica (TCE) está ligado a vários transtornos psiquiátricos, como os transtornos de ansiedade. Aproximadamente 50-60\% dos pacientes com TCAP são resistentes aos tratamentos tradicionais disponíveis e, portanto, são necessárias estratégias de apoio ao tratamento, como a atividade física (AF). Parece ser uma estratégia interessante para reduzir os sintomas da TCAP e da ansiedade. Assim, como a AF tem um papel na redução de episódios de TCAP e melhora dos sintomas de ansiedade, são necessárias mais pesquisas para esclarecer o papel da AF na TCAP, à medida que são estabelecidas correlações entre ansiedade-TCLE e ansiedadePA. Portanto, nosso objetivo é examinar a relação entre AF e ansiedade em pacientes com TCAP. Trinta e dois pacientes foram submetidos a questionários psicológicos e de AF. Um coeficiente de correlação de Pearson e uma análise de regressão linear múltipla foram realizadas para relacionar comportamento de transtorno alimentar, ansiedade e AF. Os coeficientes de correlação entre as dimensões do TCAP e ansiedade foram quase todos significativos (exceto restrição), positivos e moderados ( $\mathrm{p}<0,001)$. Assim, quanto maiores os valores do transtorno alimentar, maiores os níveis de ansiedade ( $\mathrm{p}<0,01)$. Em conclusão, nossos achados sustentam que a $\mathrm{AF}$ se correlaciona com a ansiedade em pacientes com TCAP, sugerindo que a AF pode diminuir os sintomas, como preocupações com apetite, peso e forma corporal.

Palavras chave: ansiedade, compulsão alimentar, exercício, atividade física

\section{INTRODUCTION}

Binge-eating disorder (BED) is defined by recurrent episodes of binge eating, characterised by eating an amount of food that is definitely larger than what most people would eat, in a discrete period of time (usually less than 2 hours), under the same circumstances, accompanied with a sense of lack of control (American Psychiatric Association 2013; Hilbert 2019). Life-time prevalence of BED varies from 1 to $4 \%$, with higher rates seen on women, though this gender bias is not as pronounced as in other eating disorders. Additionally, prevalence seems to be higher in adults rather than in adolescents (Davis
2015; Keski-Rahkonen \& Mustelin, 2016; Lindvall Dahlgren \& Wisting, 2017). Hereditability accounts for $41 \%$ to $57 \%$ of BED etiology (Mayhew et al., 2018), and other risk factors include childhood overweight, dieting, body dissatisfaction, negative affect, family disfunction and personality traits such as perfectionism (Bakalar et al., 2015).

BED is associated with multiple medical comorbidities beyond obesity, such as metabolic syndrome, sleep disorders, functional gastrointestinal symptoms, asthma, among others (Mitchell 2016; Olguin et al., 2017). BED is also 


\section{Physical activity and anxiety and in patients with binge-eating disorder}

associated with important psychiatric disorders and some of their characteristic psychopathology, of which the most prevalent are anxiety, depression, substance abuse and borderline personality disorders (Lindvall Dahlgren \& Wisting, 2017). Health-related quality of life of BED patients is significantly worse and is linked to greater healthcare costs (Ághet al., 2016).

Negative emotions and maladaptive emotion regulation, along with body dissatisfaction, overconcern with weight and shape, grater levels of food craving, eating as a coping strategy, and eating for purposes of reward enhancement play a nuclear role on BED psychopathology (Dingemans \& Danner, 2017; Lewer et al., 2017; Leslie et al., 2018). In fact, negative emotions like depressive an anxiety symptoms, sadness, anger and frustration (specially in an interpersonal context (Truglia et al., 2006) seem to be linked to BED, and their severity can be related with frequency and severity of binge behaviour (Arnow et al., 1992; Dingemans \& Danner, 2017; Rosenbaum \& White, 2013). The importance of negative emotions as a trigger for binge episodes, and binge behaviour as a down-regulator of these negative emotions, serving as a tool to regulate affect, are components common to many BED models and theories (Dingemans \& Danner, 2017; Kittel et al., 2015).

Anxiety, and particularly anxiety sensitivity (a cognitive style in which physiological anxiety symptoms are perceived as dangerous), seem to have an important role in negative emotions and their regulation (Taylor, 1995; Morillo Baro et al., 2016; Reigal Garrido et al., 2018). Some have even proposed that binge eating behaviours may serve as maladaptive strategies to regulate anxiety, much like nailbiting (Rosenbaum \& White, 2013; Tanaka et al., 2008). Approximately $50-60 \%$ of patients with binge eating disorder do not respond to the conventional treatments available (Linardon \& Wade, 2018; Wilson, Grilo, \& Vitousek, 2007). Thus, adaptive strategies to cope with stress and anxiety, like physical activity (PA), may be important in reducing binge eating episodes, BED symptoms and comorbidities Deboer et al., 2012; Blanchet et al., 2018; Vancampfort et al., 2014).

In a recent systematic review (Blanchet et al., 2018), it was observed that PA has a role in reducing BED episodes, improving anxiety and physical health. However, there is still evidence about this relationship in the literature. Therefore, further research is needed to clarify this issue. In this sense, our aim is to examine the relationship between PA and anxiety in patients with BED. Through a regression analysis, we expect to show that PA may improve BED symptoms through 3 mechanisms: 1) improvement in the food reward system (through biochemical pathways comparable to those used in substance abuse), reducing cravings; 2 ) down-regulation of negative affect (through PA effects on neurotransmitters such as serotonin and endorphin); 3) and improvement in appetite control, an well-known characteristic of PA. Correlations between anxiety-BED and anxiety-PA are established, but there is a need of more data on the role of PA in anxiety in BED patients.

\section{MATERIAL AND METHODS}

The present study is characterized by a cross-sectional study, in which exposure to the factor or cause is present to the effect at the same time or time interval analyzed. They apply to investigations of effects for causes that are permanent, or for factors dependent on permanent characteristics of individuals, such as the effect of PA on a particular disease (Campana et al., 2001). These studies describe a situation or phenomenon at an undefined moment, only represented by the presence of a disease or disorder, such as, for example, changes in symptoms in people with diabetes (Haddad, 2004). Thus, there is no need to know the time of exposure of a cause to generate the effect, the cross-sectional model is used when exposure is relatively constant over time and the effect (or disease) is chronic. Therefore, this model presents itself as a photograph or snapshot taken in a population by means of sampling, examining the presence or absence of exposure 


\section{da Silva Freire, dos Santos, Vaz, Lima, Axt, Murillo-Rodriguez, Monteiro, Cid, Machado \& Telles- Correia}

and the presence or absence of the effect (or disease) in the members of the sample (Fletcher, 2003).

\section{Participants}

The sample (non-probabilistic, of convenience) consisted of 32 subjects diagnosed with BED, followed on eating disorders appointments in the department of Psychiatry, Psychology, and Endocrinology of Hospital of St. Mary, Lisbon, between February and June of 2017. The diagnosis of BED was screened with a validated Portuguese version of Eating Disorder Examination Questionnaire (EDE-Q) (Machado et al., 2014), and all subjects met DSM-5 criteria for BED through Mini Plus 5.0. Only adults between 18-65 years that have not been subjected to bariatric surgery were considered. The Ethical Commission of the Santa Maria Hospital and of the Medical School of Lisbon formally allowed the conduction of this research $\left(n^{\circ} 555 / 15\right)$. In addition, all subjects gave their consented form to participate in this study.

\section{Procedures}

After the sample selection, patients were submitted to a personal interview by a trained psychologist and any questionnaires were applied, always in the same order. Data obtained was blinded to the authors of this study through a random numeric code.

\section{Instruments}

Binge Eating disorder behaviour and attitudes were assessed by the EDE-Q (Machado et al., 2014). We used the Portuguese Eating Disorder Exam Questionaire (EDE-Q), which is a widely used self-report questionnaire on disordered behaviors and attitudes and is derived from the EDE interview. EDE is usually the instrument of choice for the assessment and diagnosis of eating disorders (ED). As EDE, EDE-Q has a 28-day period, and asks directly about the frequency of major eating disorder behaviors, as well as attitudes toward key psychopathological features such as restriction, food preoccupation, concern with body shape and concern with weight (Machado et al., 2014).

Anxiety were assessed by a validated Portuguese version of the Hospital Anxiety and Depression Scale (HADS) (Pais-Ribeiro, J., 2007). It is composed of two subscales for each of the components under evaluation, used to measure and to help clinicians recognize emotional components of physical illness as well as a screening device for anxiety and depression in a general hospital setting with evidence to be helpful in assessing changes in patients' emotional state. They are calculated on a four-point scale (03 ) and considered as the sum of the questions, normal (0-7), Slight (8-10), Moderate (11-14) and Severe (15- 21) (Pais-Ribeiro, 2007).

PA was assessed by the International Physical Activity Questionnaire - short version (IPAQ). The short version of the International Physical Activity Questionnaire (IPAQ) was also used to evaluate the PA levels of the sample. Developed and tested for use in adults (age range 15-69 years) and frequently used in scientific studies, it is an instrument designed primarily for population surveillance and takes Low, Moderate and Vigorous ratings as final rating values (IPAQ Research Committee, 2005). The "Sedentary" category was considered for all individuals outside the above categories. It was first calculated the energy expenditure spent by each individual over a week (METs.min.sem) through what was reported by each individual. Each participant was asked to associate the intensity of each PA performed by the perception of oxygen capacity, according to IPAQ. The weekly calculation was made by multiplying the persisted intensity in METs (3.3 METs for light/walk, 4.0 for moderate and 8.0 for vigorous), for daily minutes spent on activity and for weekdays (e.g. 3.3 METs (light) x 90 min (walk) x 3 days/week = 891 METs.min.sem).

\section{Statistical Analysis}

The sample of this study is normal, thus descriptive statistic measures, expressed as frequency, percentage, mean (M) and standard 


\section{Physical activity and anxiety and in patients with binge-eating disorder}

deviation (SD) were used to obtain data from EDE-Q, HADS and IPAQ. In addition, a bivariant Pearson's correlation coefficient and multivariate multiple linear regression model analyses were performed to associate BED, anxiety and PA. Significance was defined at the $\mathrm{p} \leq 0.05$ level using the Fischer test.

\section{RESULTS}

Participated of this study 32 patients $(27 \mathrm{~F}$ and $5 \mathrm{M}$ ), age between 18-65 years old, with BMI varying between 27.05 and 56.69. Thirteen of them revealed being active while 19 revealed being sedentary. In addition, taking into account anxiety, 5 from 32 patients did not present anxiety and 27 presented some level of anxiety (for further details, please see table 1).

Table 1 - Descriptive data of sample.

\begin{tabular}{lcc}
\hline & $\mathbf{N}$ & $\%$ \\
\hline Gender & 27 & 84,4 \\
$\quad$ Female & 5 & 15,6 \\
Male & $45,7(10.3)$ & \\
Age (M; SD) & $40.6(6.9)$ & \\
BMI (M; SD) & & \\
Levels of Physical Activity & 19 & 59,4 \\
Sedentary & 4 & 12,5 \\
Category 1 (Low) & 8 & 25,0 \\
Category 2 (Moderate) & 1 & 3,1 \\
Category 3 (Vigorous) & & \\
Levels of Anxiety & 5 & 15,6 \\
$\quad$ (0-7) Normal & 10 & 31,3 \\
(8-10) Mild & 11 & 34,4 \\
(11-14) Moderate & 6 & 18,8 \\
(15-21) Severe & &
\end{tabular}

Table 2 shows the descriptive statistics of the values obtained by the subjects on the HADS, EDEQ and IPAQ. We also indicate the values of internal consistency, evaluated with the Cronbach's alpha coefficient. The values are all higher than the minimum of 0.60 .
Table 2 - Average values of HADS, EDE-Q and IPAQ $(\mathrm{N}=32)$.

\begin{tabular}{cccc}
\hline Instruments & Mean & SD & Alfa Cronbach \\
\hline HADS & & & \\
Anxiety & 12.06 & 3.46 & .621 \\
EDE-Q & & & \\
Restriction & 1.28 & 1.39 & .778 \\
Concern Food & 2.08 & 1.48 & .761 \\
Body Shape & 4.11 & 1.23 & .772 \\
Weight & 3.38 & 1.24 & .660 \\
Total & 2.71 & .95 & .841 \\
IPAQ & & & \\
Total METs & 564.98 & 38.04 & \\
\hline
\end{tabular}

Note: METs: metabolic equivalent task.

The correlation coefficients between the dimensions of EDE-Q and anxiety are almost all significant (except restriction), positive and moderate. Thus, the higher the eating disorder values, the higher the anxiety levels (see table 3).

Table 3 - Correlation between Anxiety and EDE-Q dimensions $(\mathrm{N}=32)$.

\begin{tabular}{lc}
\hline BED dimensions & R2 for Anxiety \\
\hline Restriction & .217 \\
Food Concern & $.460^{* *}$ \\
Body Shape Concern & $.609^{* * *}$ \\
Weight Concern & $.544^{* * * *}$ \\
Total & $.633^{* * *}$ \\
\hline
\end{tabular}

Note: $* \mathrm{p}<0.05 ; * * \mathrm{p}<0.01 ; * * * \mathrm{p}<0.001$

To check the factors that correlate with the anxiety levels, and to control the variables, we used a linear regression where the dimensions of EDE-Q, IPAQ were used as independent variables. The association is positive between anxiety (i.e., scale indicates that the higher the score, the higher the present anxiety) and the lack of PA (nominal variable 1-exercise, 2-no exercise). The same is true with concern about weight. Thus, the direction of variation in anxiety 


\section{da Silva Freire, dos Santos, Vaz, Lima, Axt, Murillo-Rodriguez, Monteiro, Cid, Machado \& Telles- Correia}

and lack of exercise is the same, so a positive association between the two variables means that the less exercise and the more worry about the body, the more anxiety. It was concluded that $29.7 \%$ of the anxiety variance is correlated with a model composed by PA and concern with weight. When $\mathrm{R}_{2}$ was adjusted, we found $43.1 \%$ of the anxiety variance correlated with the model PA and concern weight (see table 4).

Table 4: Linear regression for Anxiety, IPAQ and EDE-Q $(\mathrm{N}=32)$.

\begin{tabular}{ccccccc}
\hline Model & R2 adj & B & Beta & S & FIV & DW \\
\hline Physical Activity & & 1.95 & .635 & $2.45^{*}$ & $1.359^{*}$ & $1.609^{*}$ \\
Weight concern & & 2.90 & .352 & $4.35^{* *}$ & $1.018^{* *}$ & $1.417^{* *}$ \\
R square: .297 & .431 & & & & & \\
\hline
\end{tabular}

Note: $* \mathrm{p}<0.05 ; * * \mathrm{p}<0.01 ; \mathrm{R}^{2}$ adj: $\mathrm{R}^{2}$ adjusted; $\mathrm{B}$ : unstandardized coefficient; Beta: standardized coefficient; S: standard error; VIF: variance inflation factor; DW: Durbin-Watson

\section{DISCUSSION}

The aim of our study is to verify if there is relationship between PA and anxiety in BED patients, contributing to the existing evidence of PA as a therapeutic tool for this disorder. It is hypothesized that PA may improve BED symptoms through 3 mechanisms: 1) improvement in the food reward system (through biochemical pathways comparable to those used in substance abuse), reducing cravings; 2) downregulation of negative affect (through PA effects on neurotransmitters such as serotonin and endorphin); 3) and improvement in appetite control, an well-known characteristic of PA. Correlations between anxiety-BED and anxietyPA are established, but there is a need of more data on the role of PA in anxiety in BED patients.

Data were assessed between levels of PA, anxiety, and BED, corroborating previous studies (Hrabosky et al., 2007). Additionally, the term supported the anxiolytic effect of PA in patients with disorders, as well as different populations (Bartley et al., 2013; Broocks et al., 1998; Blumenthal et al., 1999; Karssemeijer et al., 2017;
Wedekind et al., 2010; Wegner et al., 2014; Tajik et al., 2017; Stubbs et al., 2017; Hiles et al., 2017).

From this perspective, previous data from Levine et al (1996) showed that PA may be an important aspect in the treatment of BED. In accordance with this study, the systematic review by de Blanchet et al (2018) found benefits of PA in treating patients with BED, showing decrease in episodes and other comorbidities correlated with BED, such as weight concern, which was one of the symptoms that related to the levels of PA in our findings.

In contrast, the study by Vancampfort et al. (2014) found that muscle fatigue and pain after 6 minutes walking test (MWT) were significantly higher in obese people with Binge compared with the obese and nonobese control group. Thus, the authors mentioned that people with BED face barriers that make it difficult to adhere to the practice of PA, which may explain the low levels of PA found in this population.

Above all, qualitative studies also highlight the combined therapy between exercise and diet as a way to generate a new perception of Binge patients on diet and PA (Bakland et al., 2019; Pettersen et al., 2017), suggesting that the positive experience with PA can positively influence the compensatory behavior of these individuals. In physiological terms, the review by King et al. (2011) points out that PA causes mechanisms that may contribute to appetite control, such as gastric emptying, increase of appetite-related peptides, regulation of substrate oxidation resulting from hormonal regulation and neural.

In addition, a more recent review by Blundell et al. (2015) found that exercise promotes regulation of energy demand, control of eating, increased resting metabolic rate and muscle mass, which is associated with decreased leptin and other adipocytes and, consequently, body fat. In contrast, the meta-analysis by Lavagnino et al. (2016) found that the increase in $\mathrm{BMI}$ is related to a decrease in activity of inferior frontal gyrus, ventromedial prefrontal cortex and dorsolateral prefrontal cortex, which are 


\section{Physical activity and anxiety and in patients with binge-eating disorder}

associated with inhibitory control. These data also showed that comparative studies found reduced activation in these areas in obese participants with BED compared to obese participants without BED.

\section{PRACTICAL APPLICATIONS}

Our findings support that PA correlates with anxiety in patients with BED, suggesting that PA may decrease symptoms, such as the appetite, weight and body shape concerns. From the practical point of view, the results emphasize the importance of the trainer or gymnasium staff promoting the necessary support for the prescription of training, so that it favors the training adequacy and also of making decisions about the best intensity and type of exercises to be prescribed. In line with this, we advise the minimum recommendation proposed by the American College of Sports Medicine (ACSM), 150 min.week -1 of moderate aerobic activity or 60 min.week -1 of vigorous activity to promote health (ACSM, 2013).

This work have limitations concerning the characteristics of the sample, so that the results may be influenced by the low number of participants, the heterogeneity of their demographic characteristics, and the wide age range of the participants, which are conceivable to limit our conclusions, and do not allow its extension to other groups of patients with eating disorders. Therefore, it is suggested to replicate the study with more homogeneous samples. Another limitation is its transversal naturalization, which only allows the adjustment of the model in a certain time cut, while it is presumed that longitudinal designs allow to draw solid conclusions about the causal relationships and are opportunities for our better understanding of the causal process of phenomena of interest.

\section{CONFLICT OF INTEREST}

The authors declare have not conflict of interest.

\section{REFERENCES}

1. Agh, T., Kovács, G., Supina, D., Pawaskar, M., Herman, B. K., Vokó, Z., \& Sheehan, D. V. (2016). A systematic review of the health-related quality of life and economic burdens of anorexia nervosa, bulimia nervosa, and binge eating disorder. Eating and Weight Disorders-Studies on Anorexia, Bulimia and Obesity, 21(3), 353-364.

2. ACSM. ACSM's guidelines for exercise testing and prescription. 9th ed. Lippincott Williams \& Wilkins: Philadelphia; 2013. American Psychiatric Association. (2013). Diagnostic and statistical manual of mental disorders (DSM-5®). American Psychiatric Pub.

3. Arnow, B., Kenardy, J., \& Agras, W. S. (1992). Binge eating among the obese: A descriptive study. Journal of behavioral medicine, 15(2), 155-170.

4. Bartley, C. A., Hay, M., \& Bloch, M. H. (2013). Meta-analysis: aerobic exercise for the treatment of anxiety disorders. Progress in NeuroPsychopharmacology and Biological Psychiatry, 45, 34-39.

5. Bakalar, J. L., Shank, L. M., Vannucci, A., Radin, R. M., \& Tanofsky-Kraff, M. (2015). Recent advances in developmental and risk factor research on eating disorders. Current Psychiatry Reports, 17(6), 42.

6. Bakland, M., Rosenvinge, J. H., Wynn, R., Sundgot-Borgen, J., Fostervold Mathisen, T., Liabo, K., ... \& Pettersen, G. (2019). Patients' views on a new treatment for Bulimia nervosa and binge eating disorder combining physical exercise and dietary therapy (the PED-t). A qualitative study. Eating disorders, 1-18.

7. Blanchet, C., Mathieu, M. È., St-Laurent, A., Fecteau, S., St-Amour, N., \& Drapeau, V. (2018). A systematic review of physical activity interventions in individuals with binge eating disorders. Current obesity reports, 7(1), 76-88.

8. Blumenthal, J. A., Babyak, M. A., Moore, K. A., Craighead, W. E., Herman, S., Khatri, P., ... \& Doraiswamy, P. M. (1999). Effects of exercise training on older patients with major depression. Archives of internal medicine, 159(19), 2349-2356. 


\section{da Silva Freire, dos Santos, Vaz, Lima, Axt, Murillo-Rodriguez, Monteiro, Cid, Machado \& Telles- Correia}

9. Blundell JE, Gibbons C, Caudwell P, Finlayson G, Hopkins M. Appetite control and energy balance: impact of exercise. Obes Rev. 2015;16:67-76.

10. Broocks, A., Bandelow, B., Pekrun, G., George, A., Meyer, T., Bartmann, U., ... \& Rüther, E. (1998). Comparison of aerobic exercise, clomipramine, and placebo in the treatment of panic disorder. American Journal of Psychiatry, 155(5), 603-609.

11. Campana, A.O., Padovani, C.R., Iaria, C.T., Freitas, C.B.D., De Paiva, S.A.R., Hossne, W.S. Investigação científica na área médica. 1 st ed. Sao Paulo: Manole; 2001.

12. Davis, C. (2015). The epidemiology and genetics of binge eating disorder (BED). CNS spectrums, 20(6), 522-529.

13. Dahlgren, C. L., Wisting, L., \& Rø, Ø. (2017). Feeding and eating disorders in the DSM-5 era: a systematic review of prevalence rates in nonclinical male and female samples. Journal of eating disorders, 5(1), 56.

14. DeBoer, L. B., Tart, C. D., Presnell, K. E., Powers, M. B., Baldwin, A. S., \& Smits, J. A. (2012). Physical activity as a moderator of the association between anxiety sensitivity and binge eating. Eating behaviors, 13(3), 194-201.

15. Dingemans, A., Danner, U., \& Parks, M. (2017). Emotion regulation in binge eating disorder: A review. Nutrients, 9(11), 1274.

16. Fletcher, R.H., Fletcher, S.W., Wagner, E.H. Epidemiologia clínica: elementos essenciais. 3rd ed. Porto Alegre: Artmed; 2003.

17. Haddad, N. Metodologia de estudos em ciências da saúde. 1st ed. Sao Paulo: Roca; 2004. Hilbert A. Binge-Eating Disorder. Psychiatr Clin North Am. 2019;42(1):33-43.

18. Hiles, S. A., Lamers, F., Milaneschi, Y., \& Penninx, B. W. J. H. (2017). Sit, step, sweat: longitudinal associations between physical activity patterns, anxiety and depression. Psychological medicine, 47(8), 14661477.

19. Hrabosky, J. I., White, M. A., Masheb, R. M., \& Grilo, C. M. (2007). Physical activity and its correlates in treatment-seeking obese patients with binge eating disorder. International Journal of Eating Disorders, 40(1), 72-76.

20. IPAQ Research Committee. (2005). Guidelines for data processing and analysis of the International Physical Activity Questionnaire (IPAQ)-short and long forms. http://www. ipaq. ki. se/scoring. pdf.

21. Keski-Rahkonen, A., \& Mustelin, L. (2016). Epidemiology of eating disorders in Europe: prevalence, incidence, comorbidity, course, consequences, and risk factors. Current opinion in psychiatry, 29(6), 340-345.

22. Kittel, R., Brauhardt, A., \& Hilbert, A. (2015). Cognitive and emotional functioning in bingeeating disorder: A systematic review. International Journal of Eating Disorders, 48(6), 535-554.

23. Lavagnino, L., Arnone, D., Cao, B., Soares, J. C., \& Selvaraj, S. (2016). Inhibitory control in obesity and binge eating disorder: A systematic review and meta-analysis of neurocognitive and neuroimaging studies. Neuroscience \& Biobehavioral Reviews, 68, 714-726.

24. Leslie, M., Turton, R., Burgess, E., Nazar, B. P., \& Treasure, J. (2018). Testing the addictive appetite model of binge eating: The importance of craving, coping, and reward enhancement. European Eating Disorders Review, 26(6), 541-550.

25. Levine MD, Marcus MD, Moulton P. Exercise in the treatment of binge eating disorder. Int J Eat Disord. 1996;19(2):171-7.

26. Lewer, M., Bauer, A., Hartmann, A., \& Vocks, S. (2017). Different facets of body image disturbance in binge eating disorder: a review. Nutrients, 9(12), 1294.

27. Karssemeijer, E. E., Aaronson, J. J., Bossers, W. W., Smits, T. T., \& Kessels, R. R. (2017). Positive effects of combined cognitive and physical exercise training on cognitive function in older adults with mild cognitive impairment or dementia: A meta-analysis. Ageing Research Reviews, 40, 75-83.

28. King NA, Horner K, Hills AP, Byrne NM, Wood RE, Bryant E, et al. Exercise, appetite and weight management: understanding the 


\section{Physical activity and anxiety and in patients with binge-eating disorder}

compensatory responses in eating behaviour and how they contribute to variability in exerciseinduced weight loss. $\mathrm{Br} \mathrm{J}$ Sports Med. 2012;46(5):315-22.

29. Levine MD, Marcus MD, Moulton P. Exercise in the treatment of binge eating disorder. Int $\mathrm{J}$ Eat Disord. 1996;19(2):171-7.

30. Machado, P. P., Martins, C., Vaz, A. R., Conceição, E., Bastos, A. P., \& Gonçalves, S. (2014). Eating disorder examination questionnaire: psychometric properties and norms for the Portuguese population. European eating disorders review, 22(6), 448-453.

31. Mayhew, A. J., Pigeyre, M., Couturier, J., \& Meyre, D. (2018). An evolutionary genetic perspective of eating disorders. Neuroendocrinology, 106(3), 292-306. 32. Mitchell, J. E. (2016). Medical comorbidity and medical complications associated with bingeeating disorder. International Journal of Eating Disorders, 49(3), 319-323.

33. Morillo Baro, J. P., Reigal Garrido, R.E. y Hernández-Mendo (2016). Relaciones entre el perfil psicológico deportivo y la ansiedad competitiva en jugadores de balonmano playa. Revista de Psicología del Deporte, 25(1), 31-39.

34. Olguin, P., Fuentes, M., Gabler, G., Guerdjikova, A. I., Keck, P. E., \& McElroy, S. L. (2017). Medical comorbidity of binge eating disorder. Eating and Weight Disorders-Studies on Anorexia, Bulimia and Obesity, 22(1), 13-26.

35. Pais-Ribeiro, J., Silva, I., Ferreira, T., Martins, A., Meneses, R., \& Baltar, M. (2007). Validation study of a Portuguese version of the Hospital Anxiety and Depression Scale. Psychology, health \& medicine, 12(2), 225-237.

36. Pettersen, G., Sørdal, S., Rosenvinge, J. H., Skomakerstuen, T., Mathisen, T. F., \& SundgotBorgen, J. (2017). How do women with eating disorders experience a new treatment combining guided physical exercise and dietary therapy? An interview study of women participating in a randomised controlled trial at the Norwegian School of Sport Sciences. BMJ open, 7(12), e018588.
37. Reigal Garrido, R. E., Delgado-Giralt, J., López-Cazorla, R., Hernández-Mendo, A. (2018). Perfil psicológico deportivo y ansiedad estado competitiva en triatletas. Revista de Psicología del Deporte, 27(2), 125-132.

38. Rosenbaum, D. L., \& White, K. S. (2013). The role of anxiety in binge eating behavior: A critical examination of theory and empirical literature. Health psychology research, 1(2).

39. Stubbs, B., Koyanagi, A., Hallgren, M., Firth, J., Richards, J., Schuch, F., ... \& Vancampfort, D. (2017). Physical activity and anxiety: a perspective from the World Health Survey. Journal of Affective Disorders, 208, 545552.

40. Tajik, E., Abd Latiff, L., Adznam, S. N., Awang, H., Yit Siew, C., \& Abu Bakar, A. S. (2017). A study on level of physical activity, depression, anxiety and stress symptoms among adolescents. J Sports Med Phys Fitness, 57(10), 1382-1387.

41. Tanaka, O. M., Vitral, R. W. F., Tanaka, G. Y., Guerrero, A. P., \& Camargo, E. S. (2008). Nailbiting, or onychophagia: a special habit. American Journal of Orthodontics and Dentofacial Orthopedics, 134(2), 305-308.

42. Taylor, S. (1995). Anxiety sensitivity: Theoretical perspectives and recent findings. Behaviour research and therapy, 33(3), 243-258.

43. Truglia, E., Mannucci, E., Lassi, S., Rotella, C. M., Faravelli, C., \& Ricca, V. (2006). Aggressiveness, anger and eating disorders: a review. Psychopathology, 39(2), 55-68.

44. Vancampfort, D., De Herdt, A., Vanderlinden, J., Lannoo, M., Soundy, A., Pieters, G., ... \& Probst, M. (2014). Health related quality of life, physical fitness and physical activity participation in treatment-seeking obese persons with and without binge eating disorder. Psychiatry research, 216(1), 97-102.

45. Wedekind, D., Broocks, A., Weiss, N., Engel, K., Neubert, K., \& Bandelow, B. (2010). A randomized, controlled trial of aerobic exercise in combination with paroxetine in the treatment of 


\section{Correia}

panic disorder. The World Journal of Biological Psychiatry, 11(7), 904-913.

46. Wegner, M., Helmich, I., Machado, S., E Nardi, A., Arias-Carrión, O., \& Budde, H. (2014). Effects of exercise on anxiety and depression disorders: review of meta-analyses and neurobiological mechanisms. CNS \& Neurological Disorders-Drug Targets, 13(6), 1002-1014. 